\title{
Application of laser ablation split- stream (LASS) age and tracer isotope systematics to crustal evolution and petrologic studies
}

\author{
CHRIS M FISHER ${ }^{1}$, JEFFREY VERVOORT ${ }^{2}$ AND JOHN M
} HANCHAR $^{3}$

${ }^{1}$ The University of Western Australia

${ }^{2}$ Washington State University

${ }^{3}$ Memorial University of Newfoundland

Presenting Author: chris.fisher@uwa.edu.au

The development of methods to simultaneously determine the $\mathrm{U}-\mathrm{Pb}$ age and $\mathrm{Lu}-\mathrm{Hf}$ and $\mathrm{Sm}-\mathrm{Nd}$ isotope systematics in a wide range of accessory minerals, via the laser ablation split-stream (LASS) method, represents an important advance for in situ isotope analysis. The simultaneous determination of multiple isotope systems is the preferred approach for complexly-zoned minerals where the U-Pb age is accurately and precisely tied to the measured tracer isotope composition. This especially important for studies seeking to determine initial epsilon values, which can be drastically impacted when incorrect ages are assigned. In addition, LASS analysis has proven useful in studies that seek to constrain petrogenetic processes. This talk will discuss the potential of the LASS approach, and highlight both the advantages and limitations of the method. Using multiple case studies we explore a number of applications using Lu-Hf in zircon, and Sm-Nd in rare earth element (REE)-enriched minerals like monazite, apatite, and titanite. These examples highlight the utility of the LASS approach for a variety of applications.

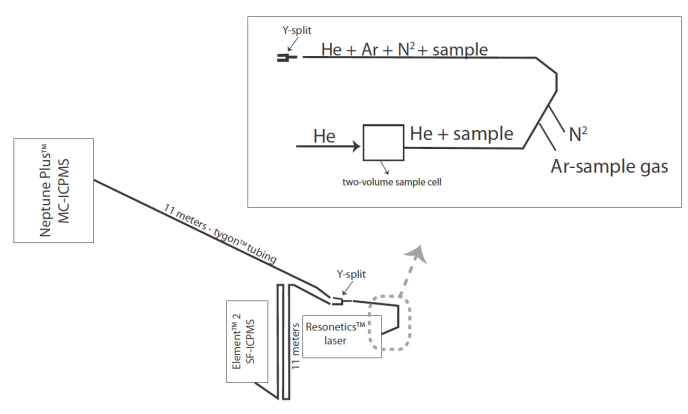

